Disclosure of Interests: None declared

DOI: 10.1136/annrheumdis-2019-eular.5063

\section{FRI0664 DISEASE ACTIVITY IS THE MAJOR DISCRIMINATOR WHEN DEFINING REFRACTORY RHEUMATOID ARTHRITIS}

Manuel Becede, Josef S. Smolen, Daniel Aletaha. Division of Rheumatology, Department of Medicine 3, Vienna, Austria

Background: Rheumatoid arthritis (RA) is characterised by the presence of a progressively destructive joint inflammation. Even in times of modern therapeutics, a subgroup of patients continues to be refractory to numerous consecutive therapeutic interventions with regards to control of inflammation and joint damage. To date, there exists no definition for refractory RA. ${ }^{1}$

Objectives: To explore different modifications of a definition for refractory RA.

Methods: Here we defined the base case of refractory RA as patients who had experienced $>3$ treatment courses (with at least one biological failure) over a minimum of 18 months since first treatment initiation (to avoid counting treatment courses that were given for a too short period), and the lack of reaching the treatment goal of low disease activity or remission (defined by a Clinical Disease Activity Index, CDAI, >10). We then modified our working definition based on these four variables (disease duration: 12/18/24 months; disease activity: moderate/high; number of treatment courses: $\geq 3 / \geq 4$; different biologic agents: $\geq 1 / \geq 2$ ).

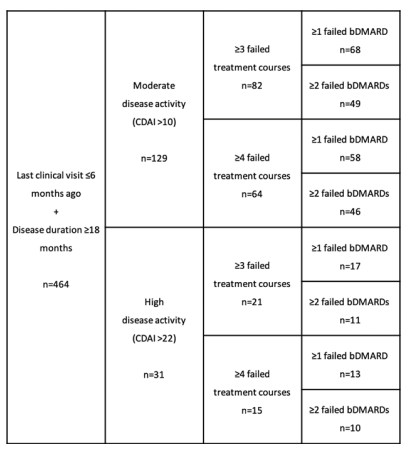

Results: From our clinic's ongoing longitudinal data set we identified 68 refractory patients out of 688 RA outpatients. There was virtually no difference based on modifying disease duration, so we kept our working definition of a minimum disease duration of at least 18 months $(n=464$; 12 months: $n=466 ; 24$ months: $n=453$ ). Changing the disease activity component of the definition had a great impact on the identified refractory RA population, by requiring high instead of moderate disease activity (MDA: $\mathrm{CDAl}>10, \mathrm{n}=129$ vs. HDA: CDAI >22, $n=31$ ). In both, the MDA and the HDA group of patients, we could observe $\geq 60 \%$ of patients, who already experienced at least three treatment courses (MDA, $n=82$ / 129; HDA, $n=21 / 31$ ). Above a half in each group qualified as refractory also with the criterion of an addition fourth failed treatment course (MDA, $n=64 / 129 ;$ HDA, $n=15 / 31$ ). When further stratifying patients based on the number of failed different biologic DMARDs, we could observe that regardless of the level of disease activity and number of failed treatment courses, most patients experienced at least one or even a second biologic agent (table).

Conclusion: The level of disease activity is the major discriminator when defining a population of refractory RA. The duration of treatment does not significantly impact the identification of refractory RA. The number of failed treatment courses and insufficient responses to biologic DMARDs further helps characterizing patients with refractory RA. Considerations of the impact of these different characteristics of refractory disease may well inform future criteria for refractory RA.

\section{REFERENCES:}

[1] Winthrop KL, Strand V, van der Heijde D, Mease P, Crow M, Weinblatt M, et al. The unmet need in rheumatology: Reports from the targeted therapies meeting 2017. Clin Immunol. 2017.
Disclosure of Interests: Manuel Becede: None declared, Josef S. Smolen Grant/research support from: AbbVie, Eli Lilly, Janssen, MSD, Pfizer Inc Roche, Consultant for: AbbVie, Amgen, AstraZeneca, Astro, Celgene, Celtrion, Eli Lilly, GlaxoSmithKline, ILTOO, Janssen, Medimmune, MSD, Novartis-Sandoz, Pfizer Inc, Roche, Samsung, Sanofi, UCB, Speakers bureau: AbbVie, Amgen, AstraZeneca, Astro, Celgene, Celtrion, Eli Lilly, GlaxoSmithKline, ILTOO, Janssen, Medimmune, MSD, Novartis-Sandoz, Pfizer Inc, Roche, Samsung, Sanofi, UCB, Daniel Aletaha Grant/research support from: AbbVie, Bristol-Myers Squibb, and MSD, Consultant for: AbbVie, Bristol-Myers Squibb, Eli Lilly, Janssen, Medac, Merck, MSD Pfizer Inc, Roche, and UCB, Speakers bureau: AbbVie, Bristol-Myers Squibb, Eli Lilly, Janssen, Medac, Merck, MSD, Pfizer Inc, Roche, and UCB

DOI: 10.1136/annrheumdis-2019-eular.5746

\section{FRI0665 THE ROLE OF CLINICAL JOINT INFLAMMATION AND ACUTE PHASE RESPONSE ON STRUCTURAL PROGRESSION OF PATIENTS WITH PSORIATIC ARTHRITIS}

Carina Borst, Farideh Alasti, Daniel Aletaha. Division of Rheumatology, Department of Medicine III, Medical University of Vienna, Vienna, Austria

Background: Psoriatic arthritis (PsA) belongs to the group of the spondylarthropathies. It is associated with psoriasis and typically seronegative for autoantibodies. PsA disease activity can be measured using the Disease Activity in Psoriatic Arthritis (DAPSA) score which is based on both clinical (e.g., swollen joint count, SJC) and systemic (e.g., C-reactive protein, CRP) markers of inflammation. [1] However, the impact of clinical and systemic inflammation on structural progression is unclear.

Objectives: To determine the contribution of clinical and systemic inflammation on structural progression of patients with PsA.

Methods: In a secondary data analysis, we analyzed patient data from the IMPACT 2 trial of infliximab (INF) vs. placebo (PLC) in patients with established PSA (disease duration in years: INF: 7.5 \pm 7.8 , PLC: $8.4 \pm 7.2$ ). Concomitant methotrexate treatment was allowed but not mandatory in both treatment arms. [2] We obtained modified Sharp-van-der-Heijde scores from X-rays performed at baseline and after one year to compute radiographic progression. We further extracted levels of SJC and CRP and calculated time-averaged SJC (taSJC) and CRP (taCRP) values to reflect the clinical and systemic inflammation, respectively. In a multivariable binary logistic regression model, we assessed the impact of taSJC, taCRP, and their interaction, on structural progression. Next, we divided patients into different subgroups depending on their taSJC and taCRP levels into active $(+)$ or inactive $(-)$. We tested whether radiographic progression was different in taSJC+ vs. taSJC- and taCRP+ vs. taCRPusing the Mann-Whitney $U$ test.

Results: 200 patients were enrolled in the IMPACT 2 trial (100 INF, 100 PLC). 151 patients were included in the analyses (76 PLC, 75 INF). Due to drop out or missing data, the remaining 49 patients were not considered for further analyses. Patients in the INF arm showed no radiographic progression $(-1.16 \pm 3.96)$, while patients in the PLC arm showed little progression $(0.74 \pm 2.98)$. We therefore focused on the 76 PLC patients. Despite the small overall progression, taSJC, taCRP, and their interaction were associated with radiographic progression (OR for taSJC: 1.24, Cl 95\%: 1.04-1.47, $\mathrm{p}=0.016$; OR for taCRP: $6.08, \mathrm{Cl} 95 \%$ : 1.12 33.03, $p=0.036$; interaction term: $p=0.097)$. Radiographic progression was higher in taSJC+ patients compared to taSJC- patients $(1.05 \pm 3.21$ and $0.56 \pm 2.30$, respectively; $\mathrm{p}=0.016$ ), as well as numerically higher without statistical significance in taCRP+ vs. taCRP- patients $(1.14 \pm 3.23$ and 0.05 \pm 2.37 , respectively; $p=0.532$ ). Also, despite the limited power of subgroup analyses, there was evidence that SJC activity plays a role in CRPpatients $(p=0.076)$, whereas CRP activity seems to be of less importance SJC- patients $(p=0.643)$

Conclusion: In patients with PsA, both clinical and systemic inflammation have impact on structural progression; in patients without systemic inflammation, clinical joint activity may still be considered as a risk factor for progression.

\section{REFERENCES:}

[1] Schoels M, Aletaha D, Funovits J, et al. Application of the DAREA/DAPSA score for assessment of disease activity in psoriatic arthritis. Ann Rheum Dis 2010;69:1441-7. Doi: :10.1136/ard.2009.122259

[2] Antoni C, Krueger GG, de Vlam K, et al. Infliximab improves signs and symptoms of psoriatic arthritis: results of the IMPACT 2 trial. Ann Rheum Dis 2005;64:1150-7. Doi: :10.1136/ard.2004.032268 
Disclosure of Interests: Carina Borst: None declared, Farideh Alasti: None declared, Daniel Aletaha Grant/research support from: AbbVie, BristolMyers Squibb, and MSD, Consultant for: AbbVie, Bristol-Myers Squibb, Eli Lilly, Janssen, Medac, Merck, MSD, Pfizer Inc, Roche, and UCB, Speakers bureau: AbbVie, Bristol-Myers Squibb, Eli Lilly, Janssen, Medac, Merck, MSD, Pfizer Inc, Roche, and UCB

DOI: 10.1136/annrheumdis-2019-eular.2353

\section{FRI0666 RHEUMATIC COMPLICATIONS OF IMMUNE CHECKPOINT INHIBITOR THERAPY: A CASE SERIES}

Benedict Moore ${ }^{1}$, Matthew $\mathrm{Ho}^{2}$, Margaret Callan ${ }^{2} .{ }^{1}$ Imperial College School of Medicine, London, United Kingdom; ${ }^{2}$ Chelsea and Westminster Hospital, London, United Kingdom

Background: Immune checkpoint inhibitor therapy reduces negative sig nals of $T$ cell activation and enables tumour-specific $T$ cells to mount a more effective response. Use of these drugs in management of malig nancy has been associated with the development of auto-immune disease. There are few published studies describing immune-related adverse events affecting the musculoskeletal system.

Objectives: This study aimed to describe the spectrum of musculoskeletal presentations in patients treated with programme death (PD)-1 and/or cytotoxic T lymphocyte associated antigen (CTLA)-4 blockade.

Methods: 16 patients were identified by retrospective review of records. All patients had received treatment with monoclonal antibodies specific for PD-1, PD ligand-1 and/or CTLA4 and had been referred for rheumatology assessment of musculoskeletal complications. We assessed clinical presentation, results of blood tests for C-reactive protein (CRP), anti-nuclear antibody (ANA), rheumatoid factor (RF) and anti-cyclic citrullinated peptide (CCP) antibody, and response to treatment.

Results: Seven males and nine females, with mean age of 56 years were evaluated. 13 patients had melanoma, two renal cell cancer and one triple negative breast cancer. Patients presented with a spectrum of musculoskeletal symptoms. Five patients displayed features most consistent with polymyalgia rheumatica (PMR), five had peripheral spondyloarthritis (SPA) features with lower limb oligoarthritis or plantar fasciitis, four had rheumatoid arthritis (RA) features with small joint polyarthritis, one had myositis with raised creatine kinase and one had new onset of gout. Only one of 16 patients was positive for RF. All patients were seronegative for anti-CCP antibodies and ANA. One patient with RA presentation had a high CRP of $39 \mathrm{mg} / \mathrm{L}$. Five patients had a mildly elevated CRP of $5-10 \mathrm{mg} / \mathrm{L}$. Other patients did not show an acute phase response. All patients received treatment with corticosteroid with benefit. Intra-articular and soft-tissue corticosteroid injections were also effective. One of two patients with RA presentation responded to sulfasalazine, and none of two patients with RA presentation responded to methotrexate. One patient with RA presentation and one with SPA presentation responded to tumour necrosis factor (TNF)alpha blockade.

Conclusion: Attenuating inhibitory signals of $T$ cell activation using immune checkpoint inhibitor therapy is associated with a range of rheumatic complications, including PMR-like as well as RA- and peripheral SPA-like presentations. The majority of patients were seronegative for RF, CCP and ANA, and had low or borderline elevated CRP. All patients showed a response to prednisolone. TNF-alpha blockade was effective for RA and SPA presentations.

\section{REFERENCES:}

[1] Mitchell EL, Lau PKH, Khoo C, et al. Rheumatic immune-related adverse events secondary to anti-programme death- 1 antibodies and preliminary analysis of the impact of corticosteroids on anti-tumour response: A case series. Eur J Cancer 2018; 105:88-102.

[2] Richter MD, Crowson C, Kottschade LA, et al. Rheumatic syndromes associated with immune checkpoint inhibitors: a single centre cohort of 61 patients. Arthritis Rheumatol 2018 doi:10.1002/art.40745.

[3] Mooradian MJ, Nasrallah M, Gainor JF, et al. Musculoskeletal rheumatic complications of immune checkpoint inhibitor therapy: A single center experience. Semin Arthritis Rheum 2018 Doi: :10.1016/j. semarthrit.2018.10.012.

Disclosure of Interests: None declared DOI: 10.1136/annrheumdis-2019-eular.2397

\section{FRI0667 \\ IS OBESITY A FACTOR OF POOR OUTCOME IN SPONDYLOARTHRITIS? AN ANALYSIS OF 638 PATIENTS}

Pascal Claudepierre ${ }^{1}$, Laure Gossec ${ }^{2,3}$, Laurent Grange ${ }^{4,5}$, Marco GarridoCumbrera $^{6,7,8}$, Emilie Desfleurs ${ }^{9}$, Francoise Alliot Launois ${ }^{10}$, René-Marc Flipo ${ }^{11,12}$. ${ }^{1}$ Henri Mondor University Hospital, Rheumatology, Créteil, France; ${ }^{2}$ Sorbonne University, Paris, France; ${ }^{3}$ La Pitié-Salpêtrière University Hospital, Rheumatology, Paris, France; ${ }^{4}$ Grenoble Alpes University Hospital, Rheumatology, Echirolles, France; ${ }^{5}$ Association Française de Lutte Antirhumatismale A.F.L.A.R, President, Paris, France; ${ }^{6}$ Universidad de Sevilla, Sevilla, Spain; ${ }^{7}$ Health and Territory Research (HTR), Sevilla, Spain; ${ }^{8}$ Spanish Federation of Spondyloarthritis Associations (CEADE), Madrid, Spain; ${ }^{9}$ Novartis Pharma, Medical Affairs, Rueil Malmaison, France; ${ }^{10}$ Association Française de Lutte Antirhumatismale A.F.L.A.R, Vice-President, Paris, France; ${ }^{11}$ Lille University, Lille, France; ${ }^{12}$ Roger Salengro University Hospital, Rheumatology, Lille, France

Background: There are few data on obese patients with axial spondyloarthritis (axSpA)

Objectives: To explore the impact of body mass index (BMI) on per sonal, professional and social life of axSpA patients.

Methods: BetweenDecember 2017 and February 2018, French patients followed for axSpA by their rheumatologists or affiliated to the French patients association AFLAR, and self-reporting axSpA, participated in the European Map of Axial Spondyloarthritis (EMAS) cross-sectional patient survey ${ }^{1}$. Sociodemographic data (including weight and height), axSpA characteristics and disease impact on personal (social interactions, frequency of social activities) and professional life (working hours, sick leave, and disability) were collected via an online questionnaire. Patients were classified in two groups according to their BMl (obese $\mathrm{BMI} \geq 30 \mathrm{~kg} / \mathrm{m}^{2}$, non-obese: $\mathrm{BMl}<30 \mathrm{~kg} / \mathrm{m}^{2}$ ) and a comparison between the two groups was conducted using chi2 or Mann-Whitney tests. There was no imputation of missing data.

Results: Data of 638 patients, mainly women 77\%, median age (years) $41.5 \pm 11.1$ were collected in France in 2018. Median BMI was $26.1 \pm 5.5$ and $22.1 \%$ patients were obese $(n=141)$. Median age was significantly higher in obese patients $(44.1 \pm 9.9$ vs $40.8 \pm 11.3 ; p=0.001)$, but there was no difference regarding gender, level of education and socio-professional categories. The obese had a longer diagnosis delay for axSPA (median $8.2 \pm 8.4$ vs $6.6 \pm 8.1$ years; $p=0.01$ ). They were more to report psoriasis $(33.8 \%$ vs $21.9 \% ; \quad p=0,005)$ and the following comorbidities: anxiety depression fibromyalgia, high blood pressure, hypercholesterolemia, diabetes and renal failure. Disease activity was also higher in the obese population: median BASDAI $6.5 \pm 1.5$ vs $5.8 \pm 1.8(p<0.001)$ and BASDAI $\geq 4$ in $92.9 \%$ vs $84.3 \% \quad(p<0.01)$. The same proportion of patients $(61.9 \%)$ has been treated by a biologic in the two groups. The impact of axSPA on personal life was more frequently reported by the obeses: $65.2 \%$ vs $48.0 \% \quad(p<0.005)$ had reduced the frequency of sport activities because of axSpA and $42.5 \%$ vs $28.3 \% \quad(\mathrm{p}<0.005)$ their sexual intercourse. There were a lower number of obeses, who had a regular physical activity (58.9\% vs 68.8\%; p>0.05) with a shorter mean duration of sport practice At the opposite, no difference was observed regarding the impact of axSpA on professional life, with a similar proportion of obese and nonobese patients reporting sick leave $(32.1 \%$ vs $24.9 \%)$ or disability $(31.9 \%$ vs $28 \%$ ). The mean number of working hours for the active people was also similar (35.5 vs 34.2 hours) in the two groups.

Conclusion: In this survey, obesity affected $22.1 \%$ of axSpA patients and was associated to a higher disease activity and a greater impact on personal life of axSpA, but not on their professional life. Obesity and its consequences have to be considered in the management of axSpA as it is already the case for psoriatic arthritis.

\section{REFERENCES:}

[1] Gossec, et al. Diagnostic Delay and Associated Factors in Axial Spondyloarthritis across Europe. Results from the European Map of Axial Spondyloarthritis Survey. Arthritis Rheumatol. 2018 Sep;70 Suppl 9:688

Acknowledgement: Survey supported by Novartis

Disclosure of Interests: Pascal Claudepierre Consultant for: Honoraria from Novartis as steering committe of this survey, Laure Gossec Grant research support from: AbbVie, BMS, Celgene, Janssen, Lilly, MSD Novartis-Sandoz, Pfizer, Sanofi, and UCB, Consultant for: AbbVie, Biogen, BMS, Celgene, Janssen, Lilly, MSD, Nordic Pharma, Novartis-Sandoz, Pfizer, Roche, Sanofi, and UCB, Consultant for: L Gossec has received honoraria from Celgene as investigator for this study, LAURENT GRANGE Consultant for: Laurent Grange has received honoraria from Amgen, Lilly and UCB and research support from Lilly, Amgen, UCB Expanscience, Mylan, Roche diagnostics and TEVA, Marco Garrido-Cumbrera Consultant for: Honoraria from Novartis as steering committe of this survey, Emilie Desfleurs Employee of: Employee of Novartis Pharma 